\title{
A geometric analysis of mastectomy incisions: Optimizing intraoperative breast volume
}

\author{
David Chopp $\mathrm{PhD}^{1,2}$, Vinay Rawlani MD¹, Marco Ellis MD¹, Sarah A Johnson BS ${ }^{1}$, Donald W Buck II MD ${ }^{1}$, \\ Seema Khan $M D^{1}$, Kevin Bethke $M D^{1}$, Nora Hansen $M D^{1}$, John YS Kim MD ${ }^{1}$
}

D Chopp, V Rawlani, M Ellis, et al. A geometric analysis of mastectomy incisions: Optimizing intraoperative breast volume. Can J Plast Surg 2011;19(2):45-50.

INTRODUCTION: The advent of acellular dermis-based tissue expander breast reconstruction has placed an increased emphasis on optimizing intraoperative volume. Because skin preservation is a critical determinant of intraoperative volume expansion, a mathematical model was developed to capture the influence of incision dimension on subsequent tissue expander volumes.

METHODS: A mathematical equation was developed to calculate breast volume via integration of a geometrically modelled breast cross-section. The equation calculates volume changes associated with excised skin during the mastectomy incision by reducing the arc length of the cross-section. The degree of volume loss is subsequently calculated based on excision dimensions ranging from $35 \mathrm{~mm}$ to $60 \mathrm{~mm}$.

RESULTS: A quadratic relationship between breast volume and the vertical dimension of the mastectomy incision exists, such that incrementally larger incisions lead to a disproportionally greater amount of volume loss. The vertical dimension of the mastectomy incision - more so than the horizontal dimension - is of critical importance to maintain breast volume. Moreover, the predicted volume loss is more profound in smaller breasts and primarily occurs in areas that affect breast projection on ptosis.

CONCLUSIONS: The present study is the first to model the relationship between the vertical dimensions of the mastectomy incision and subsequent volume loss. These geometric principles will aid in optimizing intraoperative volume expansion during expander-based breast reconstruction.

Key Words: Mastectomy incision; Mathematical model; Tissue expander; Volume

$\mathrm{M}$ aintaining breast volume and shape during mastectomy reconstruction relies heavily on two factors: adequate parenchymal volume replacement and maximal preservation of native mastectomy skin flaps. Several novel techniques, such as acellular dermis-assisted expander implant reconstruction, have allowed for significant intraoperative volume expansion and replacement of excised breast parenchyma (1-5). These techniques permit reconstructive surgeons to achieve intraoperative volume expansions that are $60 \%$ to $100 \%$ of the final breast volume (6-8). Priority has been placed on preserving native breast skin to maximize volume during the immediate reconstruction, and minimize or obviate the need for serial outpatient expansions.

Several oncological techniques may be used to minimize skin flap loss during mastectomy. Although nipple-sparing mastectomy allows for complete preservation of the skin envelope, the technique is not suited to the majority of patients $(8-10)$. Therefore, the focus is to minimize the dimension of the incision using skin-sparing mastectomy.

Skin-sparing mastectomy is commonly performed through a periareolar fusiform incision. Most surgeons use a length to width ratio of $3: 1$, which permits a tension-free closure without relative excess at the apices. Intuitively, the ability to restore postmastectomy breast volume depends on the amount of skin envelope that is conserved. Less well known is the

\section{Une analyse géométrique des incisions de mastectomie : l'optimisation du volume intraopératoire des seins}

INTRODUCTION: L'arrivée de la reconstruction mammaire par expanseur tissulaire à base de derme acellulaire a incité à s'attarder davantage sur l'optimisation du volume intraopératoire. Puisque la préservation cutanée est un déterminant essentiel de l'expansion du volume intraopératoire, les auteurs ont mis au point un modèle mathématique pour déterminer l'influence de la dimension de l'incision sur les volumes subséquents d'expansion tissulaire.

MÉTHODOLOGIE : Les auteurs ont mis au point une équation mathématique pour calculer le volume des seins, en intégrant une coupe transversale des seins selon un modèle géométrique. L'équation permet de calculer les changements de volume associés à la peau excisée pendant l'incision de mastectomie tout en réduisant la longueur de l'arc de coupe transversale. Le degré de perte volumique est ensuite calculé d'après les dimensions de l'excision, qui oscillent entre $35 \mathrm{~mm}$ et $60 \mathrm{~mm}$.

RÉSULTATS : Il existe une relation quadratique entre le volume des seins et la dimension verticale de l'incision de mastectomie, de manière que des incisions plus larges sur le plan incrémentiel entraînent une perte volumique disproportionnellement plus élevée. La dimension verticale de l'incision de mastectomie, plus que la dimension horizontale, est d'une importance cruciale pour maintenir le volume des seins. De plus, la perte volumique prévue est plus marquée en présence de seins plus petits et s'observe surtout dans les régions qui touchent la projection des seins en ptose.

CONCLUSIONS : La présente étude est la première à exposer le lien entre les dimensions verticales de l'incision de la mastectomie et la perte de volume subséquente. Ces principes géométriques contribueront à optimiser l'expansion intraopératoire du volume pendant la reconstruction mammaire à l'aide d'un expanseur.

relationship of breast volume loss to the dimensions of these periareolar fusiform incisions. Therefore, the present study aimed to quantify the degree of volume loss associated with increasing the dimensions of the fusiform mastectomy incision using mathematical modelling.

\section{METHODS}

Mathematical breast shape model

A geometrical breast model was created to determine the amount of volume loss associated with a standard fusiform mastectomy incision. The breast shape was defined by the following parameters: A (base width), B (height) and $\mathrm{C}$ (projection), which are in respective relation to an $\mathrm{x}, \mathrm{y}$ and $z$ coordinate plane (Figure 1). The base width of the breast shape was formed by an ellipse as shown in the front view ( $x$-y plane) and given by equation 1 :

$$
\left(\frac{x}{A / 2}\right)^{2}+\left(\frac{y}{(B-C / 2) / 2}\right)^{2}=1 .
$$

The projection of the breast is similar to a hemisphere, and is illustrated in the top view ( $\mathrm{z}$-x plane). The cross-section of the breast is shown in the side view ( $y-z$ plane). The shape used to model the breast

${ }^{1}$ Department of Surgery, Feinberg School of Medicine, Northwestern University, Chicago; ${ }^{2}$ Department of Engineering Sciences and Applied

Mathematics, McCormick School of Engineering and Applied Sciences, Northwestern University, Evanston, Illinois, USA

Correspondence: Dr John YS Kim, Department of Surgery, Feinberg School of Medicine, Northwestern University, 675 North Saint Clair Street,

Galter Suite 19-250, Chicago, Illinois 60611, USA. Telephone 312-695-6022, fax 312-695-5672, e-mail jokim@nmh.org 


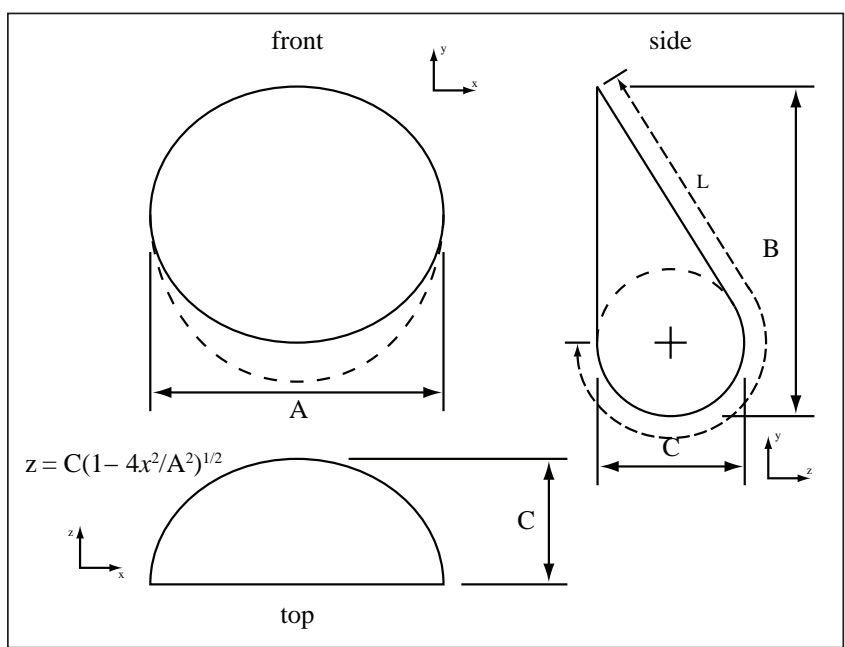

Figure 1) Schema of the initial breast model parameters: A (base width), $B$ (height) and C (projection). Notably, L represents the arch length, which is shortened during excision of the theoretical fusiform mastectomy incision

was based on the description of the McGhan Style 133 MV Tissue Expander (Allergan Inc, USA).

Using this breast model, the area was integrated continuously over the base width $(\mathrm{x})$ to calculate the volume of the breast. The vertical height of the breast along the chest wall, which parallels the breast meridian, was defined as $\tau$ and the inframammary fold was defined as $-\tau$. These points were fixed and only dependant on the horizontal position, $\mathrm{x}$, by equation 2 :

$$
\tau(x)=\frac{B-C / 2}{2 A} \sqrt{A^{2}-4 x^{2}} .
$$

The superior aspect of the breast mound was defined by a line drawn from $\tau$ to form a tangent with the elliptical sphere of the lower breast mound shape. The area of the cross-section varies as a function of base width $(\mathrm{x})$ and is given by equation 3 :

$$
\operatorname{Area}(x)=\tau(x) C(x)+\frac{C^{2}(x)}{8}\left(\pi+\arcsin \left(\frac{y_{0}(x)+\tau(x)}{C(x) / 2}\right)\right) .
$$

The model assumed a simple elliptical relationship between the maximum height of the cross-section and the $\mathrm{x}$ position so that the maximum projection is given by equation 4 :

$$
C(x)=C \sqrt{1-\frac{4 x^{2}}{A^{2}}}
$$

The point $(\mathrm{yO}, \mathrm{z} 0)$ where the tangent line touches is also dependent on $\mathrm{x}$ (equations 5 and 6):

$$
\begin{gathered}
y_{0}(x)=\frac{\tau(x)\left(3(C(x) / 2)^{2}-4 \tau^{2}(x)\right)}{\left(4 \tau^{2}(x)+(C(x) / 2)^{2}\right)} \\
z_{0}(x)=\frac{4 C(x) \tau^{2}(x)}{\left(4 \tau^{2}(x)+(C(x) / 2)^{2}\right)} .
\end{gathered}
$$

After substitution of equations 2, 4 and 5 into the cross-sectional area, equation 3 , the volume of the breast may be calculated by integrating the cross-sectional area as a function of the base width $(\mathrm{x})$. Using the parameters A (base width), B (height) and C (projection), the volume of the breast shape is given by equation 7 :

$$
V=\int_{-A / 2}^{A / 2} \operatorname{Area}(x) d x=\frac{A C}{12}\left(4 B+(\pi-2) C-C \arcsin \left(\frac{C(C-2 B)}{2 B^{2}-2 B C+C^{2}}\right)\right) .
$$

Note that the expression on the right of equation 7 is only valid for the expression of $\mathrm{C}(\mathrm{x})$ given in equation 4 , which describes the original breast volume before excision.

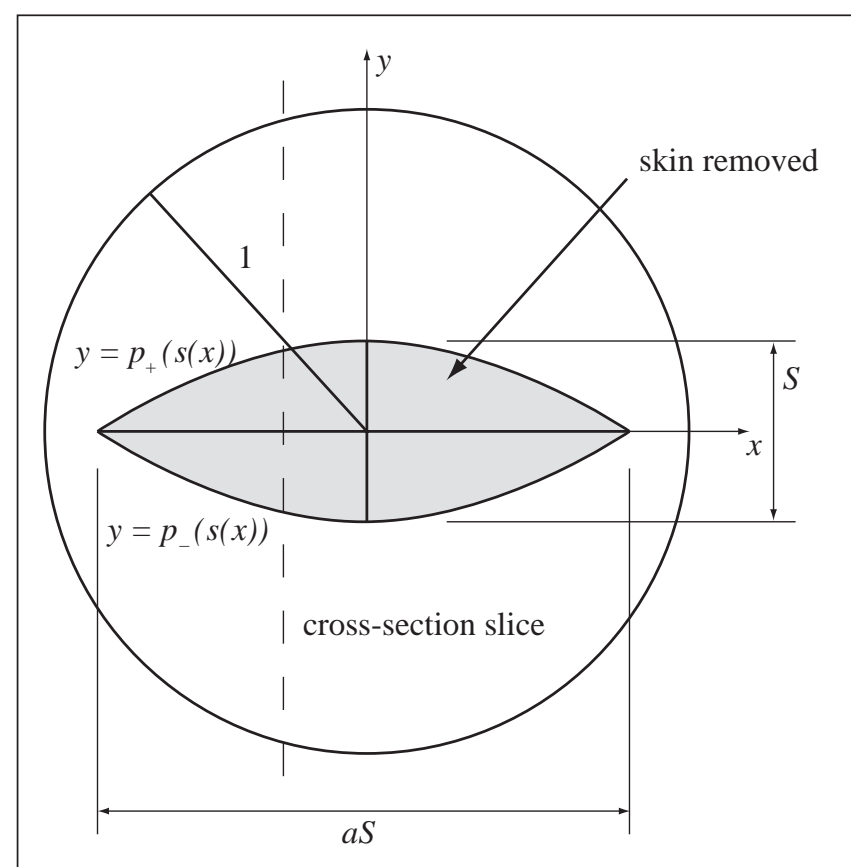

Figure 2) Schematic representation of the fusiform mastectomy incision, which is excised. The region is a fusiform circular shape with a vertical dimension (height), S, and a horizontal dimension (length), aS

\section{Mathematical mastectomy incision model}

The excised skin was assumed to be a fusiform circle in shape following the arc on the surface of the breast (Figure 2). If $\mathrm{s}$ is the arclength from $\mathrm{x}=0$ along the surface, then the fusiform circle of the incision has upper and lower bounds given by the following equation:

$$
p_{ \pm}(s)= \pm \frac{1}{4}\left(S\left(1-a^{2}\right)+\sqrt{S^{2}\left(1+a^{2}\right)^{2}-16 s^{2}}\right) .
$$

This choice of incision will result in a shape such that the excised region has a maximal vertical dimension, $\mathrm{S}$, and horizontal length, aS, in which a is a fixed constant, typically $2.5<\mathrm{a}<3$. Given the horizontal position, $\mathrm{x}$, the corresponding value of $\mathrm{s}(\mathrm{x})$ is given by the following:

$$
s(x)=\frac{A}{2} \int_{0}^{2 x / A} \frac{\sqrt{1-\frac{4 C^{2}}{A^{2}} \chi^{2}}}{\sqrt{1-\chi^{2}}} d \chi .
$$

We assume that the points at the same $\mathrm{x}$ location will be stitched together, removing the shaded region in Figure 2. The remodelled shape after removal of the excised tissue will be assumed to maintain the same structural shape as before; however, $\tau$ and $-\tau$ remain fixed (ie, chest wall and inframammary fold).

The cross-sectional profile of our model is critical for modelling the breast volume following skin excision with the mastectomy incision. The arclength, L, represents the curvilinear distance from superior pole to the inframammary fold. The arc also varies as a function of base width $(\mathrm{x})$ and is given by the following equation:

$$
L(x)=\sqrt{\left(y_{0}(x)-\tau(x)\right)^{2}+z_{0}^{2}(x)}+\frac{C(x)}{2}\left(\pi+\arcsin \left(\frac{y_{0}(x)+\tau(x)}{C(x) / 2}\right)\right) .
$$

The model is developed such that the theoretical fusiform incision was subtracted from the arclength as a function of base width (x), thereby reducing the surface area of the breast envelope during integration. The arc length minus the vertical dimension of the mastectomy incision is given by the following equation:

$$
\begin{aligned}
& L(x)-\left(p_{+}(s(x))-p_{-}(s(x))\right) \\
& \quad=\sqrt{\left(y_{0}^{\prime}(x)-\tau(x)\right)^{2}+z_{0}^{\prime 2}(x)}+\frac{C^{\prime}(x)}{2}\left(\pi+\arcsin \left(\frac{y_{0}^{\prime}(x)+\tau(x)}{C^{\prime}(x) / 2}\right)\right) .
\end{aligned}
$$




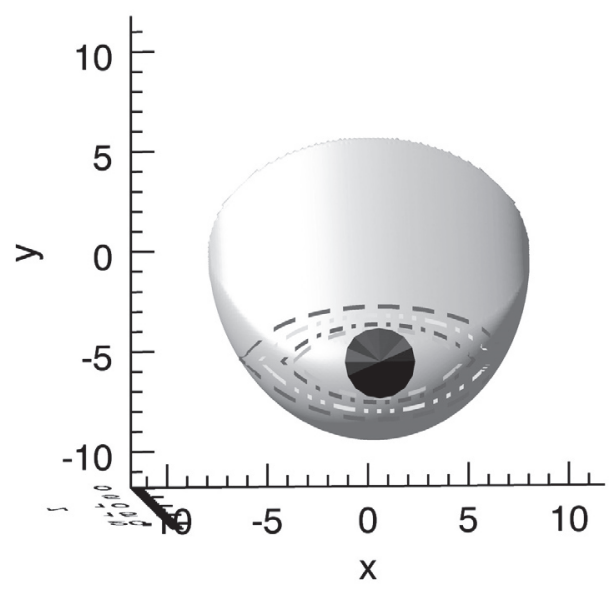

Figure 3) Incision lines of various sizes drawn on the breast model. The breast model is shown with the following parameters: $A=16 \mathrm{~cm}, B=15 \mathrm{~cm}, C=$ $6.6 \mathrm{~cm}$. All fusiform incisions are drawn with a length to width ratio, $a=2.5$. The dotted lines (from interior to exterior) correspond to incision sizes: $35 \mathrm{~mm} \times$ $87.5 \mathrm{~mm}, 40 \mathrm{~mm} \times 100 \mathrm{~mm}, 50 \mathrm{~mm} \times 125 \mathrm{~mm}$, and $60 \mathrm{~mm} \times 150 \mathrm{~mm}$

The only remaining free parameter is projection, $\mathrm{C}^{\prime}$, which is the new height after excision. Because the value for $\mathrm{C}^{\prime}(\mathrm{x})$ cannot be computed explicitly, the model is completed using numerical results.

Substituting $\mathrm{C}^{\prime}(\mathrm{x})$ into the cross-sectional area formula, equation 3 , determines the new volume of the breast after theoretical excision of skin as a result of the mastectomy incision. The integral in Equation 8 (below) was computed numerically using an adaptive quadrature algorithm in Matlab software (2008a, The MathWorks, USA).

$$
V=\int_{-A / 2}^{A / 2} \operatorname{Area}(x) d x=\int_{-A / 2}^{A / 2} \tau(x) C^{\prime}(x)+\frac{C^{\prime 2}(x)}{8}\left(\pi+\arcsin \left(\frac{y_{0}(x)+\tau(x)}{C^{\prime}(x) / 2}\right)\right) d x .
$$

\section{Volume calculations}

Breast volume loss following the theoretical excision of various sizes of mastectomy incisions was calculated using the aforementioned mathematical model. Dimensions of the mastectomy incisions were modified in three ways to achieve two specific goals. The height of the vertical incision dimension, $\mathrm{S}$, was increased while maintaining a fixed height to width ratio, a. This allowed determination of the relationship between the overall size of the mastectomy incision and breast volume loss; the height of the vertical incision dimension, S, was increased while maintaining a fixed horizontal dimension, aS; and the width of the horizontal dimension, aS, was increased while maintaining a fixed vertical dimension, S. Comparison of the results from the two latter modifications enables one to determine whether increasing the vertical dimension, S, or horizontal dimension, aS, has a greater effect on breast volume loss.

Specifically, the relationship between overall mastectomy size and breast volume loss was achieved as outlined. The vertical dimension, S, of the fusiform incision was increased from $35 \mathrm{~mm}$ to $40 \mathrm{~mm}, 50 \mathrm{~mm}$ and $60 \mathrm{~mm}$, while maintaining a fixed width: height ratio, a, of 2.5 to yield incisions of the following dimensions: $35 \mathrm{~mm} \times 87.5 \mathrm{~mm}, 40 \mathrm{~mm} \times$ $100 \mathrm{~mm}, 50 \mathrm{~mm} \times 125 \mathrm{~mm}$ and $60 \mathrm{~mm} \times 150 \mathrm{~mm}$. For simplicity, calculations were first performed using a standard breast size with the following dimensions: $\mathrm{A}=16.0 \mathrm{~cm}, \mathrm{~B}=15.0 \mathrm{~cm}$ and $\mathrm{C}=6.6 \mathrm{~cm}$ and then with various breast sizes through modification of parameters $A, B$ and $C$. In cases in which the planned excision width exceeded the actual base width, the excision width was narrowed (ie, a was reduced so that $\mathrm{Sa} \leq$ $s(\mathrm{~A} / 2)$ ). Three-dimensional models of the breast were created based on the mathematical model to further represent volume changes.

To determine whether the vertical dimension, S, or horizontal dimension, aS, had a greater effect on breast volume loss, the following comparison was made: A plot of incision dimension (vertical or

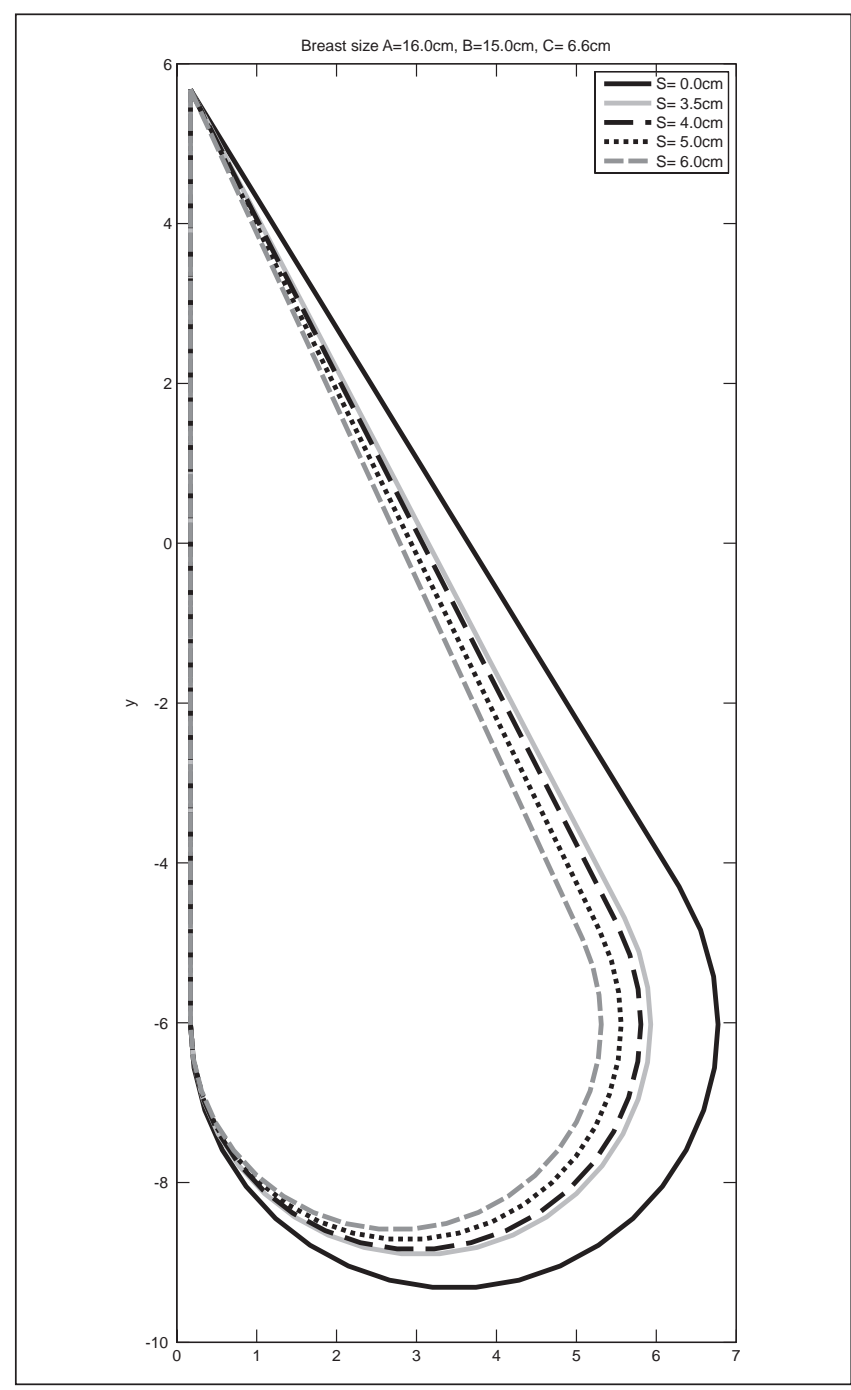

Figure 4) Cross-sectional view at midline for the four incision dimension cases. The solid black curve is the original cross-section before excision using the following parameters: $A=16 \mathrm{~cm}, B=15 \mathrm{~cm}, C=6.6 \mathrm{~cm}$. The curves correspond to incision sizes: $35 \mathrm{~mm} \times 87.5 \mathrm{~mm}$ (solid grey curve), $40 \mathrm{~mm} \times$ $100 \mathrm{~mm}$ (dashed black curve), $50 \mathrm{~mm} \times 125 \mathrm{~mm}$ (dotted black curve) and $60 \mathrm{~mm} \times 150 \mathrm{~mm}$ (dashed grey curve). S Height of the vertical incision dimension

horizontal) versus breast volume was made and the slopes of the two were compared. To determine the effect of increasing the vertical dimension, the height, $\mathrm{S}$, was increased from $35 \mathrm{~mm}$ to $60 \mathrm{~mm}$ while maintaining a fixed horizontal dimension, aS, of $87.5 \mathrm{~mm}$. To determine the effect of increasing the horizontal dimension, the width, aS, was increased from $87.5 \mathrm{~mm}$ to $150 \mathrm{~mm}$ while maintaining a fixed vertical dimension, $\mathrm{S}$, of $35 \mathrm{~mm}$.

\section{RESULTS}

As expected, the derived three-dimensional mathematical model demonstrated a relationship between excised breast skin and potential reconstruction volume. A regression analysis of the excision width and volume revealed a quadratic relationship. When the excision width exceeded the breast base width $(\mathrm{Sa}>\mathrm{A})$, the relationship between excision width and volume was linear.

Figure 3 (lines from the inside to the exterior) illustrates four theoretical excisions to be used for comparison: $35 \mathrm{~mm} \times 87.5 \mathrm{~mm}$, $40 \mathrm{~mm} \times 100 \mathrm{~mm}, 50 \mathrm{~mm} \times 125 \mathrm{~mm}$, and $60 \mathrm{~mm} \times 150 \mathrm{~mm}$. The curves in Figure 4, showing the cross-sectional area at the midline $(x=0)$, illustrate the anticipated expansion changes when $A=16 \mathrm{~cm}$, 


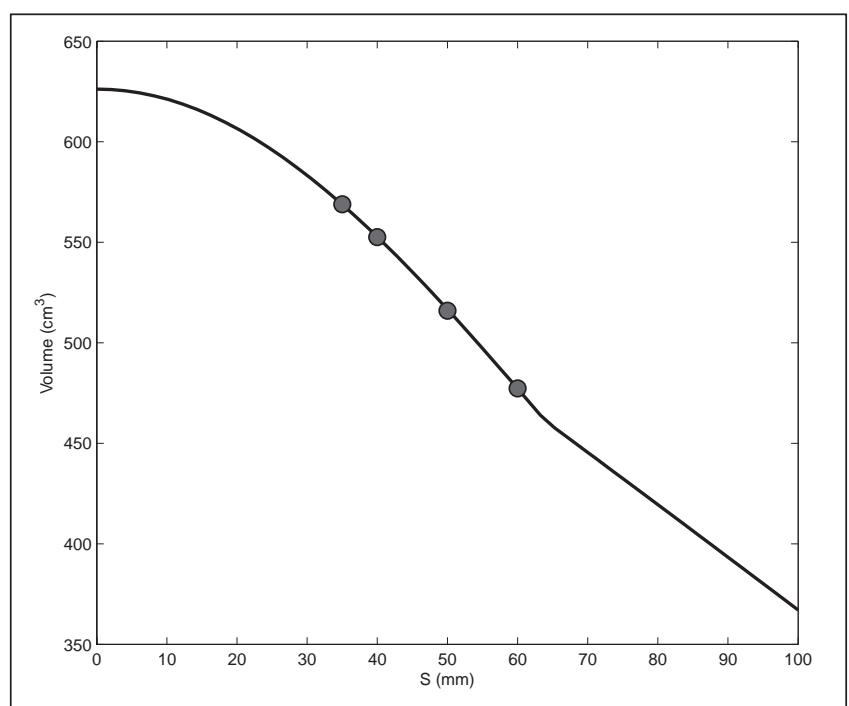

Figure 5) Change of volume with varying excision widths (S) for various initial breast size parameters. The dots (from left to right) correspond to $S=$ $35 \mathrm{~mm}, 40 \mathrm{~mm}, 50 \mathrm{~mm}$ and $60 \mathrm{~mm}$, and also correspond to the lines in Figure 3, moving from the interior to the exterior. Similarly, the dots correspond to the curves in Figure 4, with the matching $S$ values

$\mathrm{B}=15 \mathrm{~cm}, \mathrm{C}=6.6 \mathrm{~cm}$ and $\mathrm{S}$ varies for the four cases. Integration of the cross-sectional area as shown in equation 8 , in which the height to width ratio is held fixed at $\mathrm{a}=2.5$, results in the volume calculation presented in Figure 5. The circular points correspond to the four cases described above. Three-dimensional models were constructed from the mathematical model and are represented in Figures 6 and 7. These wire frames display the volume changes and demonstrate that the volume loss was primarily a reduction in breast projection and ptosis. The resulting loss of volume was measured as a percentage of the initial volume for different breast sizes and incision dimensions. These results for $\mathrm{a}=2.5$ are shown in Table 1 .

Increases in the vertical dimension of the fusiform excision resulted in a nonlinear change in breast volume. For example, for a breast of fixed size of $A=16 \mathrm{~cm}, \mathrm{~B}=15 \mathrm{~cm}$ and $\mathrm{C}=6.6 \mathrm{~cm}$, an incision of $40 \mathrm{~mm} \times 100 \mathrm{~mm}$ resulted in $11.7 \%$ volume loss, whereas an incision of $50 \mathrm{~mm} \times 125 \mathrm{~mm}$ resulted in $17.5 \%$ volume loss and an incision of $60 \mathrm{~mm} \times 150 \mathrm{~mm}$ resulted in $23.8 \%$ volume loss. This can be visualized by the quadratic dependence of volume on $\mathrm{S}$ in Figure 5 up to values of $\mathrm{S}$ in which $\mathrm{Sa}=\mathrm{s}(\mathrm{A} / 2)$ and the mastectomy incision model becomes limited. Additionally, it was observed that volume change was more pronounced as the breast size decreased in projection and base width.

Increasing the vertical dimension, $\mathrm{S}$, of the mastectomy incision results in greater volume loss than increasing the horizontal dimension, aS. This is evident in Figure 8, in which the negative slope of the 'vertical dimension' curve is greater than the slope of the 'horizontal dimension' curve.

\section{DISCUSSION}

Preservation of mastectomy skin flaps is vital to restoration of natural breast volume and shape during breast reconstruction. With the advent of acellular-based tissue expander reconstruction, the magnitude of intraoperative volume expansion is critically related to the extent of skin preservation. The present study demonstrated a clear mathematical relationship between the dimensions of the mastectomy incision and loss of breast volume during mastectomy. It also identified the vertical dimension as the critical component of the mastectomy incision in terms of breast volume loss. Although multiple assumptions were made to simplify the complex architecture of the breast, the model demonstrated a predictable volumetric change after total

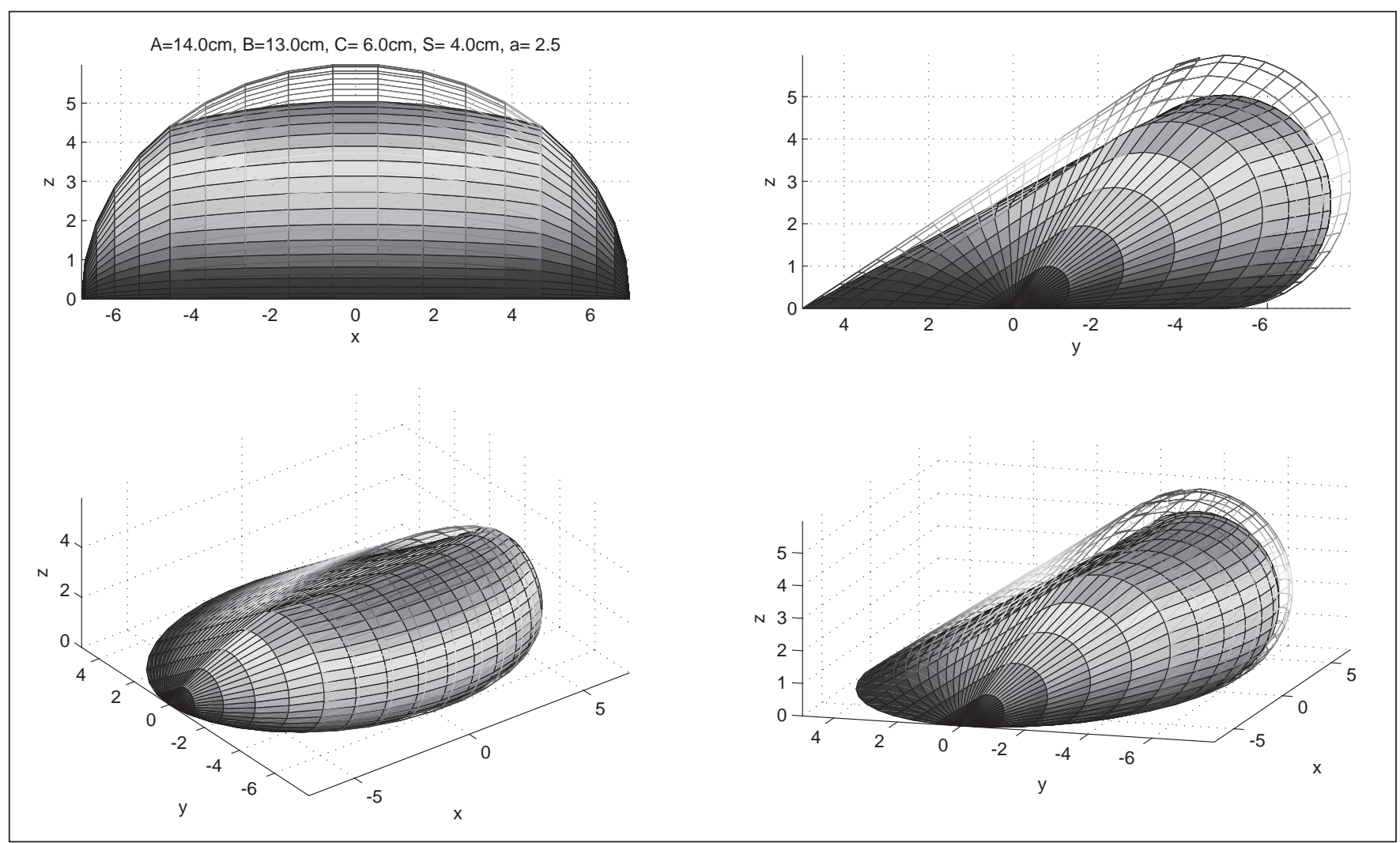

Figure 6) Sample reconstruction with $A=14 \mathrm{~cm}, B=13 \mathrm{~cm}, \mathrm{C}=6 \mathrm{~cm}$, and an incision size of $40 \mathrm{~mm} \times 100 \mathrm{~mm}$. The original volume is shown in wireframe and the final volume is solid. This example corresponds to the third (from the top) excision line in Figure 3. a Length to width ratio 


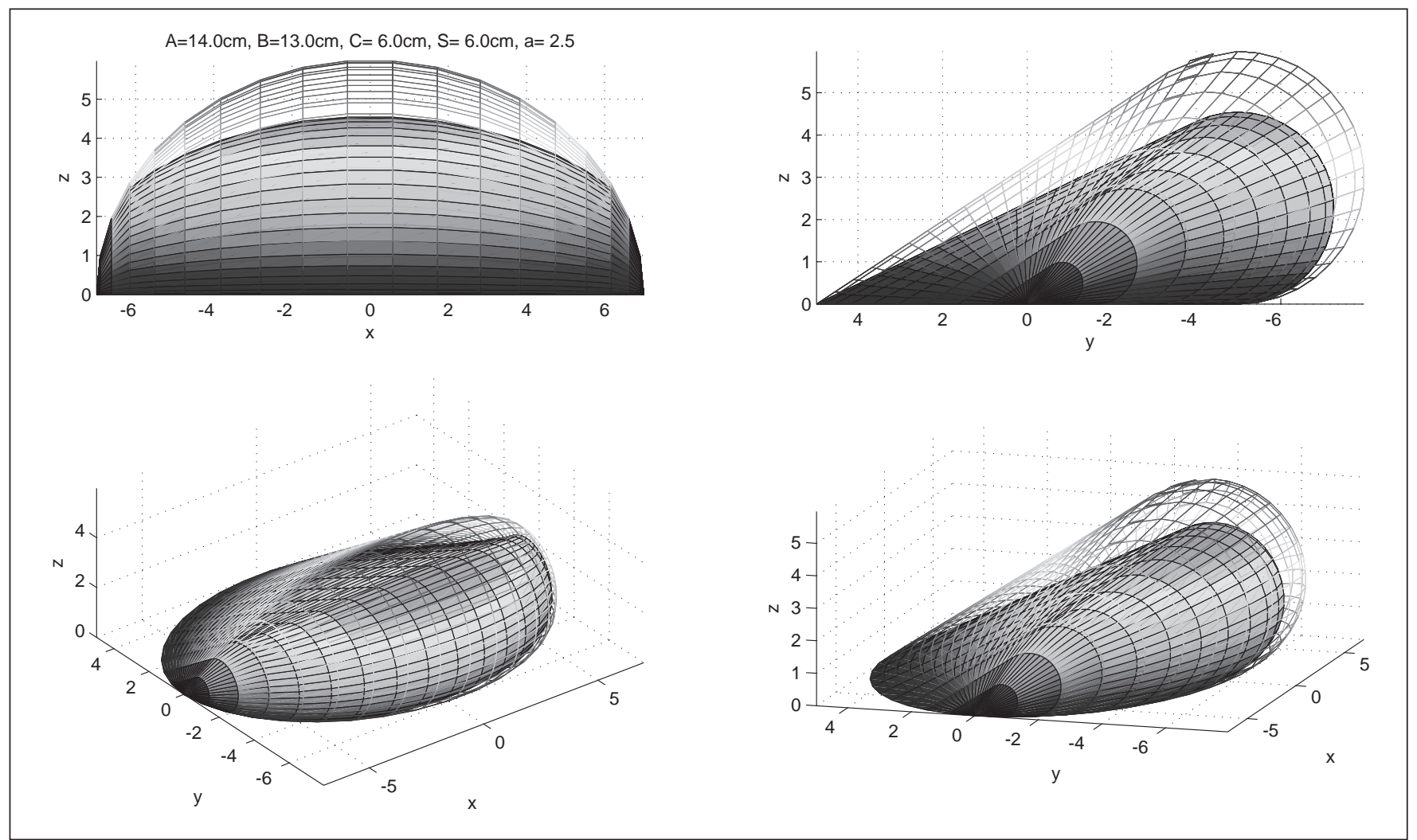

Figure 7) Sample reconstruction with $A=14 \mathrm{~cm}, B=13 \mathrm{~cm}, \mathrm{C}=6 \mathrm{~cm}$, and an incision size of $60 \mathrm{~mm} \times 150$ mm and length to width ratio (a) $=2.5$. The original volume is shown in wireframe and the final volume is solid. This example corresponds to the first (from the top) excision line in Figure 3

TABLE 1

Net volume loss for various initial breast sizes and fusiform incision dimensions

\begin{tabular}{|c|c|c|c|c|c|c|}
\hline \multicolumn{3}{|c|}{ Breast dimensions } & \multicolumn{4}{|c|}{ Incision dimensions (S $\times$ [aS]), $\mathrm{mm}$} \\
\hline A & B & C & $35 \times 87.5, \%$ & $40 \times 100, \%$ & $50 \times 125, \%$ & $60 \times 150, \%$ \\
\hline 11 & 10 & 4.9 & 16.60 & 20.80 & 27.60 & 33.20 \\
\hline 12 & 11 & 5.2 & 14.70 & 18.60 & 26.10 & 31.30 \\
\hline 13 & 12 & 5.6 & 12.80 & 16.30 & 23.70 & 29.10 \\
\hline 14 & 13 & 6.0 & 11.30 & 14.40 & 21.10 & 27.20 \\
\hline 15 & 14 & 6.3 & 10.20 & 13.00 & 19.20 & 25.90 \\
\hline 16 & 15 & 6.6 & 9.20 & 11.70 & 17.50 & 23.80 \\
\hline
\end{tabular}

In all cases, the length to width ratio (a) $=2.5$. aS Horizontal dimension; $\mathrm{S}$ Vertical dimension

mastectomy. Several breast sizes, approximated by the McGhan Style 133 MV Tissue Expander, were analyzed with incrementally larger excision patterns. The percentage change in volume after mastectomy ranged from $9.2 \%$ to $33.2 \%$. Regression analysis demonstrated a quadratic relationship between mastectomy incision size and breast volume loss during mastectomy, which is exaggerated in breasts of smaller sizes. Comparison of incision dimension-volume curves also demonstrated the vertical dimension of the mastectomy incision, as opposed to the horizontal dimension, had the greatest influence on breast volume loss. The results from our model suggest that the maximal intraoperative breast volume that can be achieved after mastectomy depends directly on the square of the incision height (ie, the vertical dimension). This concept is especially important when attempting to achieve maximal intraoperative volumes via the acellular dermis-assisted technique. It is well established that the benefit of releasing the pectoralis muscle (and creating the paired acellular dermal sling) is to allow greater utilization of excess skin. By appreciating the relationship between the vertical component of the incision

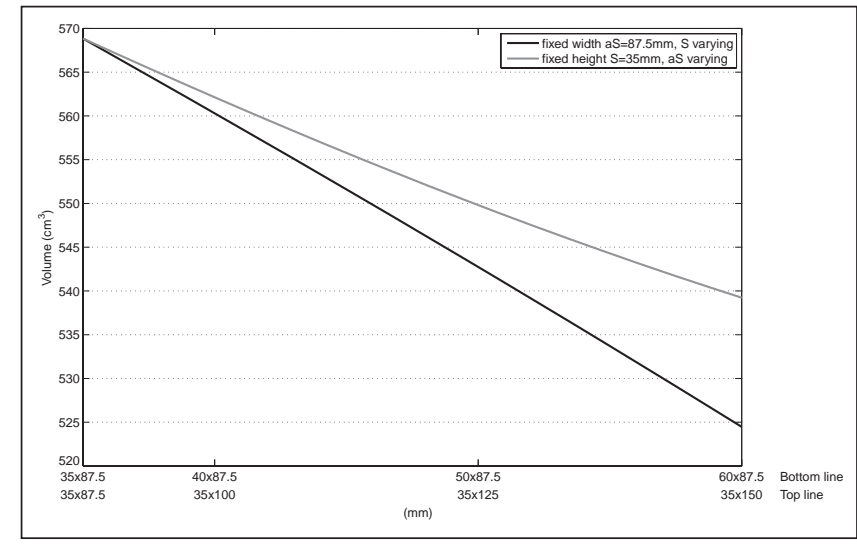

Figure 8) The effect of increasing the vertical or horizontal incision (S) on breast volume. Bottom line: Volume curve when increasing the vertical dimension, S, from $35 \mathrm{~mm}$ to $60 \mathrm{~mm}$ while maintaining a fixed horizontal dimension, aS, of $87.5 \mathrm{~mm}$. Top line: Volume curve when increasing the horizontal dimension, aS, from $87.5 \mathrm{~mm}$ to $150 \mathrm{~mm}$ while maintaining a fixed vertical dimension, S, of $35 \mathrm{~mm}$. Surface areas of skin excision were equal between the groups. Increasing the vertical dimension, $S$, of the fusiform incision results in greater volume loss than increasing the horizontal dimension, aS, as demonstrated by the greater negative slope of the 'vertical dimension' curve

and breast volume loss, the reconstructive surgeon will now be able to preserve additional skin and, thus, additional volume at the time of mastectomy, which will translate into larger immediate fill volumes and improved outcomes - a true marriage between mastectomy and reconstruction.

When performing a modified radical mastectomy, current practice patterns recommend incorporating the nipple-areolar complex in the fusiform incision (11). It is well known that the dimensions of the 
incision can contribute to overall skin flap viability and cosmesis. For instance, if the vertical dimension of the incision is excessive, subsequent skin closure will result in untoward tension and will increase the risk for skin flap necrosis. Likewise, if the horizontal dimension is too short, excess skin will result in dog-ears on closure (12). To address these concerns, Coombs and Royle (13) created a mathematical model to aid in drawing a skin ellipse for mastectomy. Their model proposed a theoretical apical angle of $30^{\circ}$ with a length-to-width ratio of 3:1 on a flat surface. In most cases, the mastectomy incision is hand drawn and varies greatly among surgeons; analysis of hand-drawn fusiform incisions by varying surgeons has been shown to produce a range of apical angles between $37^{\circ}$ and $74^{\circ}$. In addition to a strikingly wide variability, all angles were greater than the recommended $30^{\circ}$ by Coombs and Royle (13). The result of these angles is unnecessary resection of skin and addition of added stress during closure $(14,15)$. Tilleman et al (16) concluded that the fusiform incision from obtuse angles results in skin waste of up to $230 \%$. Intuitively, and validated by the present mathematical model, it is also possible to correlate these larger apical angles, which have greater vertical dimensions, with more theoretical breast volume loss.

From the breast surgeon's perspective, the mastectomy incision serves to grant reasonable surgical access to all quadrants of the breast. In addition, by using larger fusiform incisions, the resultant mastectomy skins flaps will be smaller, with a lower potential for flap-tip necrosis. From the reconstructive surgeon's perspective, larger fusiform incisions will have greater vertical dimensions, which is the limiting

\section{REFERENCES}

1. Breuing KH, Warren SM. Immediate bilateral breast reconstruction with implants and AlloDerm slings. Ann Plast Surg 2005;55:232.

2. Bindingnavele V, Gaon M, Ota KS, Kulber DA, Lee DJ. Use of acellular cadaveric dermis and tissue expansion in postmastectomy breast reconstruction. J Plast Reconstr Aesthet Surg 2007;60:1214-8.

3. Salzberg CA. Nonexpansive immediate breast reconstruction using human acellular tissue matrix graft (NHADM). Ann Plast Surg 2005;57:1.

4. Topol BM, Dalton EF, Ponn T, Campbell CJ. Immediate single-stage breast reconstruction using implants and human acellular dermal tissue matrix with adjustment of the lower pole of the breast to reduce unwanted lift. Ann Plast Surg 2008;61:494-9.

5. Eppley BL. Revascularization of acellular human dermis (HADM) in subcutaneous implantation. J Aesth Surg 2000;21:291.

6. Spear SL, Parikh PM, Reisin E, Menon NG. Acellular dermis-assisted breast reconstruction. Aesth Plast Surg 2008;32:418-25.

7. Rawlani V, Buck D, Heyer K, Kim JYS. Tissue expander breast reconstruction using pre-hydrated human acellular dermis. Plast Reconstr Surg. (In press).

8. Rawlani V, Fiuk J, Johnson SA, et al. The effect of incision choice on outcomes of nipple-sparing mastectomy reconstruction. Can J Plast Surg. (In press) geometric factor in achieving maximal intraoperative expansion. Thus, the ideal mastectomy incision is one that provides sufficient surface area of exposure to the breast surgeon, yet limits vertical loss of skin for the reconstructive surgeon. Based on our mathematical model, the ideal incision can be achieved by minimizing the vertical component, such that it stretches slightly beyond the confines of the nipple areolar complex, and extending the incision along the horizontal dimension laterally to a level that produces sufficient access to the breast. In a separate mathematical analysis that is not reported in the present study, increasing the horizontal dimension was found to have a greater effect on improving the exposure area for mastectomy dissection than increasing the vertical dimension (except in cases in which the length to width ratio [a] was less than 1.5).

\section{SUMMARY}

Our three-dimensional mathematical model demonstrates the critical relationship between the vertical dimension of the mastectomy incision and the potential intraoperative volume. Specifically, it clearly demonstrates that the breast replacement volume will vary with the square of the vertical height of the incision. The clinical application of this geometric relationship will help to optimize mastectomy incisions such that maximal intraoperative fill volumes can be obtained. Marrying this knowledge with acellular dermis techniques will equate to fewer postoperative visits for expansion, reduced potential time to implant exchange and may potentially enhance aesthetic outcomes from rapid expansion that can create more natural, ptotic breast topography $(6,7)$.

9. Voltura AM, Tsangaris TN, Rosson GD. Nipple-sparing mastectomy: Critical assessment of 51 procedures and implications for selection criteria. Ann Surg Oncol 2008;15:3396-401.

10. Spear SL, Hannan CM, Willey SC, Cocilovo C. Nipple-sparing mastectomy. Plast Reconstr Surg 2009;123:1665-73.

11. Fischer JE. Mastery of Surgery, 5th edn. Lippincott Williams \& Wilkins 2001:1304-11.

12. Chretien-Marquet B, Cailou V, Brasnu D, Bennaceur S, Buisson T. Description of cutaneous excision and suture using a mathematical model. Plast Reconstr Surg 1999;103:145-50.

13. Coombs NJ, Royle GT. How to draw the skin ellipse for a mastectomy. Ann R Coll Surg Engl 1999;81:248-50.

14. Moody BR, McCarthy JE, Sengelmann RD, The apical angle: A mathematical analysis of the ellipse. Dermatol Surg 2001;27:61-3.

15. Klapper, M. The 30-degree angle revisited. J Am Acad Dermatol 2005;53:831-2.

16. Tilleman TR, Tilleman MM, Krekels GA, Neumann MH. Skin waste, vertex angle, and scar length in excisional biopsies: Comparing five excision patterns-fusiform ellipse, fusiform circle, rhomboid, mosque, and S-shaped. Plast Reconstr Surg 2004;113:857-61. 